\title{
EL NIÑO DE LA CALLE EN LA PRODUCCIÓN LITERARIA DE JULIETA PINTO: TRADICIÓN E INNOVACIÓN DE LOS TEMAS Y TÓPICOS DE ESTA FIGURA EN $A$ LA VUELTA DE LA ESQUINA Y ABRIR LOS OJOS
}

\author{
Street children in Julieta Pinto's literary production: tradition and innovation \\ in this character themes and topics in A la vuelta de la esquina and Abrir los ojos
}

Dorde Cuvardic García*

\begin{abstract}
RESUMEN
En la producción de Julieta Pinto es común encontrar el personaje del niño de la calle, figura clave en la historia de la literatura costarricense y latinoamericana. Objetivo del presente artículo es delimitar los temas y tópicos que caracterizan su representación en la escritora costarricense, así como el encuadre ideológico utilizado en la construcción de su perfil. ¿Quedan representados como granujas, como héroes de la modernidad urbana? ¿Son sujetos desvalidos, dignos de la conmiseración del lector? En cuentos como "¿Le limpio, don?", "Navidad 1973", o "Le llevo, doña?" (A la vuelta de la esquina), o "No puedo ir", "El secuestro" o "La gente no entiende" (Abrir los ojos), Julieta Pinto se sitúa en el segundo de los paradigmas mencionados para ofrecer su visión personal de esta figura.

Palabras clave: niño de la calle, literatura costarricense, Julieta Pinto, cuento costarricense.
\end{abstract}

\begin{abstract}
In Julieta Pinto's literary production street children, key figures in Costa Rican and Latin American Literary History, are common. This article's goal is to delimit the themes and topics characterizing the representation of this character in this Costa Rican writer, as well as the ideological standpoint used by Pinto in constructing this character's profile. Are they represented as scoundrels, or as heroes of urban modernity? Are they helpless individuals, worthy of the reader's sympathy? In short-stories such as "¿Le limpio, don?", "Navidad 1973", or "Le llevo, doña?" (A la vuelta de la esquina), or "No puedo ir", "El secuestro" or "La gente no entiende" (Abrir los ojos), Julieta Pinto takes the hero's approach to offer her personal vision of this character. Key Words: Street children, Costa Rican literature, Julieta Pinto, Costa Rican short-story.
\end{abstract}

Universidad de Costa Rica. Docente Escuela de Filología, Lingüística y Literatura. Costa Rica.

Correo electrónico: dcuvardic@yahoo.es

Recepción: 02/03/16. Aceptación: 19/06/16 


\section{Introducción}

El niño de la calle surge como personaje protagonista en la literatura occidental en el siglo XIX (Charles Dickens, Víctor Hugo; Clarín; Pérez Galdós). Asimismo, la literatura latinoamericana comenzó a representarlo como figura individualizada en este último siglo. Se procedió, en aquel entonces, a la estetización de la pobreza infantil, cuando diversos autores costumbristas latinoamericanos del siglo XIX publicaron textos sobre el mataperro, llamado así porque el chico de la calle, para combatir su aburrimiento, arroja piedras a los perros. Así, el sintagma que designa una de sus actividades más visibles en el espacio público se constituyó, por antonomasia, en sustantivo que llegó a definir a este tipo social.

Muy visible ha sido la presencia de esta figura en el cine latinoamericano, desde el encuadre de la denuncia social, a partir de Los olvidados (1950), de Luis Buñuel, línea continuada posteriormente por Pixote (1981), Ciudad de Dios (2002), o Estación Central de Brasil (1998) ${ }^{1}$. Asimismo, y en correspondencia con un fenómeno social que ha sido visibilizado en los últimos años, ha surgido un cine sobre niños de la calle de procedencia centroamericana que, desde el papel del emigrante -por lo general, guatemalteco y hondureño- atraviesa México con el objetivo de llegar a los Estados Unidos, como ocurre con La jaula de oro, La breve y precoz vida de Sabina Rivas, o Sin nombre, en lo que podemos llamar 'cine de emigración de la Frontera Sur'.

Asimismo, el niño de la calle cuenta con una amplia tradición en la producción literaria costarricense. Una modalidad la ofrece el chico que, aunque cuenta con una figura paterna o materna o con algún familiar (hermano o hermana, tío o tía, abuelo o abuela) que fiscaliza de vez en cuando su comportamiento, pasa todo el día en la calle, protagonizando travesuras e, incluso, en ocasiones, acciones delictivas. En el caso de La desheredada (1881), de Benito Pérez
Galdós, vemos la paulatina transformación de Mariano Rufete, el hermano de la protagonista, Isidora, de niño travieso a adolescente criminal, cambio simbolizado por el apodo que él mismo emplea, el de 'Pecado'. Otros niños y adolescentes, en todo caso, no traspasan esta barrera y realizan lo que la sociedad hegemónica designa como travesuras, acciones que, si tomamos prestada la terminología legal, pueden llegar a ser infracciones, pero nunca delitos. Es el caso de Marcos Ramírez (1952) y de Mi madrina (1950), dos novelas autobiográficas de Carlos Luis Fallas. Los protagonistas tienen familiares de los que dependen, pero deambulan ociosos todo el día en un espacio predominantemente rural y, para combatir su aburrimiento, realizan travesuras.

A partir de la década de 1970, las representaciones literarias costarricenses del niño de la calle son preferentemente urbanas, sin abandonarse la representación realista o costumbrista. Frente al mundo de las drogas de los sectores marginales adultos, que acapara la mayor parte del argumento de la novela de Los dorados, de Sergio Muñoz (1999, primera edición; 2009, segunda edición), el Capítulo XX de esta última novela, en particular, está dedicado a las correrías de un chico -Miguelen las calles de San José. Es un niño gregario que tiene varios amigos: 'Quesillo', la 'Purru' y 'Ameba'. Miguel -'Piojo' para sus amigospertenece a la categoría del niño de la calle ya mencionada en la producción de Carlos Luis Fallas. Tiene un hogar -madre, en este caso- y un techo en el que dormir, pero deambula todo el día para 'matar' el tiempo. Carece de control materno, ya que esta última figura trabaja en un puesto ambulante. El Capítulo XX de Los dorados incorpora los clásicos tópicos sobre el niño de la calle: la representación de este espacio como escuela de la vida, el descubrimiento de los diferentes sectores del centro degradado de la urbe o el robo en los puestos de frutas para obtener alimento ${ }^{2}$. Hablamos de un niño que, a pesar del medio moralmente corrupto en el que está obligado a vivir -o a sobrevivir-, nunca pierde su inocencia. 


\section{El chico de la calle en las colecciones de cuentos de Julieta Pinto: A la vuelta de la esquina y Abrir los ojos}

El encuadre de la niñez como edad ingenua y del niño como sujeto inocente predomina en los cuentos de Julieta Pinto. No todos los personajes infantiles de la producción literaria de esta escritora son niños de la calle. Frente a este último, el niño abandonado o el huérfano es el protagonista de "¿Y yo?" (Abrir los ojos), que espera infructuosamente la llegada al hogar de acogida (el orfanato) de una familia que termine por adoptarle ${ }^{3}$. Es una situación prototípica de la temática del niño huérfano, escena que podemos identificar, por ejemplo, al inicio de Oliver Twist (1837-1839). Correlativamente, el abandono de un niño recién nacido se relata en el cuento "Una vida muy corta" (Abrir los ojos), que muere durante la madrugada ante la puerta de un hogar de acogida. Los personajes no quedan identificados, pero se infiere que el sujeto que abandona al niño en la puerta del hospicio es la madre de la adolescente que ha tenido al bebé.

El chico de la calle es una figura relevante de los cuentos de Julieta Pinto. Hemos seleccionado aquellos cuentos de las colecciones A la vuelta de la esquina (1975, primera edición; 1998, segunda edición) y Abrir los ojos (1982) que incorporan esta figura. Julieta Pinto publicó estas colecciones en los años setenta y ochenta, en el marco de una 'deficiente' modernidad urbana, con todas las problemáticas sociales que provocó (pobreza, burocracia), modernidad que representarían desde una perspectiva crítica otros escritores de la época como Daniel Gallegos o Carmen Naranjo, con muestras como Diario de una multitud (1974) ${ }^{4}$. El Centro de San José se convirtió, a partir de estas coordenadas sociales, en un espacio prototípico de la literatura de la marginalidad urbana en la segunda mitad del siglo XX. En el caso de Julieta Pinto, la degradación de las clases populares en sectores marginales se aprecia en el cuento “Le limpio, don?" (A la vuelta de la esquina $)^{5}$, donde la Avenida Central y el Parque
Central representan los espacios cotidianos del niño limpiabotas, como ocurre también en el Capítulo XX de Los dorados.

Julieta Pinto practica, en su producción dedicada al niño huérfano y al chico de la calle, lo que ha sido catalogado como "literatura de circunstancias'. Podemos definir esta última como toda aquella producida por un escritor o escritora motivado por su compromiso personal con una causa social o política: en todas estas ocasiones se denuncia una 'lacra' social que -desde su papel de intelectual- pretende erradicar. La redacción de estos textos literarios suele ser apresurada -aluden a un referente social que se encuentra en primera línea de la discusión de la opinión pública- y se deja en segundo plano, en muchas ocasiones, la calidad literaria del texto. Este último sirve, más que todo, para exponer una problemática colectiva. La práctica de diversos géneros literarios se constituye en un canal de denuncia y se asume que su difusión -en librerías, escuelas, etc.representará un eficaz medio -entre otros- para que sea erradicada la problemática, mediante la movilización de la opinión pública y la creación de propuestas legislativas. Es una literatura de finalidad pragmática. Además de la literatura de denuncia de las condiciones sociales deplorables en las que vive la niñez (explotación laboral y/o sexual; orfandad; desinterés educativo del grupo familiar en su desarrollo como persona y ciudadano), otra manifestación de la literatura de circunstancias -ya de carácter político y no estrictamente social- es la 'poesía panfletaria' producida en la retaguardia de la Guerra Civil Española, donde la transmisión de la propaganda, que se desea veloz y efectiva, deja en segundo plano, de nuevo, a la calidad literaria. En el caso de Julieta Pinto, ha de vincularse la publicación de las colecciones de cuentos dedicadas a la niñez marginal con su preocupación personal por la situación vital de este grupo etario y por la erradicación de la problemática social -la pobreza- en la que vive. De hecho, en las mismas décadas -hablamos de los años setenta y ochenta- en las que escribe cuentos de esta temática, Julieta Pinto participó en puestos directivos del Patronato Nacional de 
la Infancia (PANI), entre 1978 y 1982, y dirigió el Instituto Mixto de Ayuda Social (IMAS), entre 1978 y 1979. Educar y denunciar por medio de la literatura es un propósito que esta escritora costarricense asumió en momentos en los que se involucró con organismos orientados a la protección de la infancia.

El título de la primera colección de cuentos, A la vuelta de la esquina, alude de entrada a un tópico asociado al niño de la calle: el encuentro imprevisto del transeúnte -estereotipado como pequeñoburgués egocéntrico, preocupado por sus pequeños problemas cotidianos- con un niño que, de pie o sentado en el suelo, pide limosna. Es decir, inesperadamente podemos enfrentarnos con una pobreza que hemos decidido ocultar y olvidar. La esquina es un espacio relacionado con la experiencia de la marginalidad. Es un lugar de gran confluencia de transeúntes, motivo por el que los mendigos y los vendedores ambulantes lo eligen para pedir o para pregonar sus mercancías. El título de la segunda colección de cuentos, Abrir los ojos, también alude a la necesidad de enfrentarnos y de observar una pobreza urbana omnipresente. Podemos, incluso, unir los dos títulos en una síntesis que simboliza el propósito perseguido por Julieta Pinto: 'a la vuelta de la esquina' no nos queda más remedio que 'abrir los ojos' y enfrentarnos al problema de la pobreza infantil urbana.

A diferencia de Carlos Luis Fallas, tal como ocurre con Mi madrina y Marcos Ramírez, la representación del niño de la calle en Julieta Pinto es predominantemente urbana. Hablamos de niños que juegan o deambulan en el espacio público porque sus padres no pueden ocuparse de ellos; en particular, no pueden enviarlos a la escuela o al colegio mientras trabajan. Además, tampoco quedan incorporados en el sector laboral informal infantil. En Carlos Luis Fallas el niño de la calle no es mendigo, vendedor callejero, delincuente o chico ocioso que deambula por las cosas solo o acompañado de amigos. Diferente es el caso de la representación literaria del niño de la calle a partir de los años setenta, donde los últimos cuatro papeles sociales mencionados pasan a tener protagonismo en la representación de esta figura. Son niños huérfanos o adolescentes que sus padres han desentendido por extensos intervalos de tiempo.

¿Qué actividades realiza el niño de la calle en los cuentos de Julieta Pinto? En "No puedo ir" (Abrir los ojos), Juan y Ulises piden limosna. Rogelio, protagonista de "La gente no entiende" (Abrir los ojos), también emprende esta actividad, en su caso para comprar zhiner, droga que le permitirá 'vivir' en un mundo de felicidad que no tiene cuando está en plena posesión de su conciencia. También, pide limosna el protagonista de "El secuestro", niño raptado por una banda integrada en el comercio internacional de órganos. Una excepción es el limpiabotas de “Le limpio, don?” (A la vuelta de la esquina), que desempeña un oficio asociado tanto a la vida adulta como a la niñez. Se utiliza como título la principal interpelación empleada por el sujeto que realiza este oficio para llamar la atención de los potenciales clientes. Se infiere por este paratexto que el relato se ocupará de su cotidianeidad laboral. Al protagonista de "Le limpio, ¿don?" le acusan de robo sin ningún tipo de prueba: "No pudieron probar nada los detectives. Le había limpiado los zapatos al gringo antes de que se le perdieran los cien pesos, eso fue todo." (p. 91). Este cuento nos permite comprobar que el concepto de 'ratero' es una etiqueta que otorga muchas veces la sociedad disciplinaria a un niño de la calle que no comete acciones delictivas ni gamberradas, sino que simplemente se desempeña en un oficio callejero. En el cuento “LLe llevo, doña?” (A la vuelta de la esquina), el niño se ofrece como ocasional cargador de la compra realizada por las amas de casa en el mercado. Mientras que en el siglo XIX encontramos al cargador adulto, el lépero, en el XX este oficio queda desempeñado, en la ficción literaria, por sujetos infantiles. Ya no hablamos del transporte de sacos o maletas, sino de las bolsas del supermercado.

Como ya mencionamos, los niños de la calle de los cuentos de Pinto cuentan con figuras parentales. Es el caso de "No puedo ir" (Abrir los ojos): la madre de Juan favorece que su hijo pida limosna, mientras que su padre es borracho 
y agrede a la familia. En "¿Le limpio, don?” (A la vuelta de la esquina), el padre del niño protagonista también es limpiabotas. La figura paterna es, por lo general, un agresor alcohólico y abandona, temporal o definitivamente, el núcleo familiar. La figura maternal tampoco es modélica. En ocasiones, la madre trata con desprecio a un hijo que regresa a casa sin plata.

Las organizaciones de protección de la infancia de la calle, los reformatorios -donde reciben una educación correctiva tanto niños como adolescentes- y la policía también quedan incorporadas en las ficciones que nos ocupan en este artículo. El niño de "La gente no entiende" (Abrir los ojos) aspira droga en el parque con el objetivo inmediato o expectativa de ser enviado al reformatorio y recibir algún tipo de protección. El niño limpiabotas de "¿Le limpio, don?" (A la vuelta de la esquina), está constantemente alerta para huir de los policías que, en cualquier momento, le pueden atrapar durante el ejercicio de su trabajo ilegal: "Por la acera de enfrente viene uno de los tombos que lo llevó al reformatorio. Se agacha para acomodar el cajón y que no lo vea. Sólo eso le faltaba, que se lo carretearan otra vez." (1998: 90).

El hambre está presente en la cotidianeidad del niño de la calle. Así sucede con Rogelio en "La gente no entiende" (Abrir los ojos): "Yo también tengo hambre siempre, pero no le digo nada [a mi madre], y por no verle los ojos, salgo de la casa ligero" (2004: 16); o con el niño protagonista de "El secuestro (Abrir los ojos) mientras mendiga en las calles: "Cuántos días sin comer nada más que un pedazo de pan que Mario [su compañero] compartía conmigo" (2004: 87). En "No puedo ir" (Abrir los ojos) uno de los niños decide ir al Rositer cuando no aguanta más el hambre. Correlativamente, los niños de la calle enfrentan la tentación de robar una fruta en un puesto ambulante, una situación o motivo muy común, asimismo, en las versiones decimonónicas de esta figura. Es el caso de “ ¿Le llevo, doña? (A la vuelta de la esquina):

Ahora las frutas son más ajenas. Cuestan una moneda de tamaño mediano o grande, de esas que nunca sobran en su casa. De vez en cuando se roba una naranja de las más pequeñas, pero el vendedor tiene ojos hasta por la espalda y grita llamando al policía, con alaridos más fuertes que los de don Roque. (1998: 165).

Asimismo, se abre paso en estos cuentos el tema de la drogadicción infantil, como en "La gente no entiende" (Abrir los ojos), donde Rogelio, el niño protagonista, huele zhiner de una botella en el parque del barrio, o el grupo de niños que toman pastillas en "El secuestro" (Abrir los ojos). Se retrata la figura de un niño consumidor de estupefacientes que carece de cualquier criterio para discriminar las consecuencias negativas de su empleo. Como ya explicamos, se ofrece un enfoque del chico de la calle como ser esencialmente ingenuo, ignorante de la degradación moral de la urbe moderna.

Un tópico común en la representación del niño de la calle es la atracción ejercida por los escaparates. Estos últimos ofrecen productos que responden a sus deseos e ilusiones, pero que se encuentran fuera de sus posibilidades económicas, frente al adulto, que tiene capacidad de compra. El abismo existente entre el deseo y la posesión de la mercancía se expone en “¿Le limpio, ¿don?" (A la vuelta de la esquina): "Conocía las vidrieras con dulces y pasteles, y aunque volviera la cabeza a otro lado eran adivinados por su estómago, en un concierto de ruidos extraños." (1998: 88). También, es el caso de Juan y Ulises. En "No puedo ir" (Abrir los ojos), ambos niños "caminan lentamente, deteniéndose frente a los escaparates de las tiendas, atisbando el momento de extender la mano para recibir una limosna." (2004: 75). En "Navidad 1973" (A la vuelta de la esquina), Ofelia, la niña limosnera, queda atraída por las muñecas que se exhiben en el escaparate de una juguetería: "no ve el tren ni los carros de cuerda, ni el despliegue de luces y árboles de Navidad, no tiene ojos más que para aquella ventana donde unas muñecas se agrupan ordenadamente. [...] Se adhiere a la ventana y sus manos sucias acarician el vidrio" (1998: 116). En la relación que el niño de la calle tiene con los escaparates se distingue esta figura de la del ratero. Este último roba las billeteras de los adultos que se han detenido en los escaparates, ensimismados 
ante las promesas que ofrecen mercancías sobre las que tienen poder de compra ${ }^{6}$. En una especie de inversión irónica, los adultos que observan las vitrinas representan, para el ratero, el verdadero escaparate que debe desvalijarse. En cambio, el niño de la calle, definido ante todo por la carencia (de afecto, de abrigo, de dinero), sueña o imagina ante el escaparate la posesión de unos juguetes o de unos alimentos a los que no puede acceder. En el presente, el escaparate permite asumir, coyunturalmente, como una simple posibilidad latente, la satisfacción de esta carencia.

Es relevante la relación que tiene el personaje del niño de la calle con el dinero. Es el caso del cuento "El niño de Junto al cielo" (Lima Hora Cero, 1954), del peruano Enrique Congrains Martín, en momentos en los que el neorrealismo social se encontraba en auge: el protagonista encuentra en un billete en el suelo y su compañero le convence para que ambos 'inviertan' este dinero en la compra de revistas que, supuestamente, después revenderían. En el marco de la picaresca, su 'amigo' terminará por quedarse con la 'plata' ganada. En el caso de los niños de la calle de los cuentos de Julieta Pinto, tienen unas pocas monedas (nunca billetes) que quieren gastar en alimentos, para saciar el hambre, o en aquellos objetos que colman los deseos infantiles. Por lo general, sobredimensionan el valor de las monedas que tiene y, cuando están a punto de comprar aquel objeto que, pretendidamente, va a colmar sus ilusiones, llega el desengaño: es poco lo que pueden comprar con el dinero conseguido. Así ocurre en ¿Le llevo, doña?" (A la vuelta de la esquina): "Ahora las frutas son más ajenas. Cuestan una moneda de tamaño mediano o grande" (1998: 165). También, le ocurre esta situación al niño de “Le limpio, don?” (A la vuelta de la esquina).

En Julieta Pinto, el chico de la calle es un ser desprotegido, iluso, caracterizado por la carencia (de afecto familiar), de educación, de recursos económicos. Esta literatura se ofrece ante el lector como un documento social de denuncia de una situación indeseable e insostenible en momentos en los que se debaten, a nivel internacional, los Derechos Humanos de la Niñez.

\section{Conclusiones}

La narrativa de Julieta Pinto sobre el niño de la calle se puede considerar como un ejemplo de literatura de circunstancias, de literatura de urgencia. Esta escritora costarricense se desempeñó como Presidenta del PANI, organización de defensa de los derechos de la niñez, y del Instituto Mixto de Ayuda Social, dedicada a combatir la pobreza. En este sentido, la narrativa de Julieta Pinto sobre la niñez de la calle, en el momento de su publicación, tuvo un fin pragmático, el de denunciar léase, visibilizar, por medio de la ficción- las condiciones sociales deplorables en las que vivía una parte importante de la niñez urbana en la Costa Rica de los años setenta y ochenta. Considero que el fin pragmático de la denuncia también conlleva la representación de escenas altamente estereotipadas, de larga tradición en la literatura de las relaciones entre la niñez y la pobreza: la visita de una pareja sin hijos a un hospicio en busca de un niño a quien adoptar -" ¿Y yo?" (Abrir los ojos)-, o el abandono y muerte de un bebé frente a la puerta de un hogar de acogida -"Una vida muy corta" (Abrir los ojos)-. Son cuentos que sacrifican la originalidad narrativa en favor de la denuncia. Se prima el contenido frente al ejercicio estilístico $\mathrm{y}$, ocasionalmente, frente a la verosimilitud narrativa. La ausencia de esta última es evidente, por ejemplo, en "El secuestro" (Abrir los ojos), donde los secuestradores, una vez que han extraído un órgano a un niño, le dejan en libertad en el extranjero y, poco después, un familiar le encuentra en un parque de una ciudad extraña, lejos del país natal.

En el discurso literario se han desarrollado tres acercamientos ideológicos, a la hora de representar al niño de la calle. El primero de ellos es el de este tipo social como héroe de la modernidad cultural. Dentro de este encuadre, queda representado desde una acendrada estetización. Es el caso de las representaciones 
costumbristas de esta figura social. El segundo es el del niño de la calle como sujeto desvalido que debe ser objeto de protección por parte de la familia o las instituciones dedicadas al bienestar social de la niñez. Se puede apreciar en la tradición melodramática, presente en Dickens (Oliver Twist) y en Chaplin (El Chico, 1921). Es un discurso que proviene de las ciencias sociales y de las políticas gubernamentales. Un tercer discurso sobre el niño de la calle es el de la criminalización, ocasionalmente ofrecido por la policía y los medios de comunicación: es un sujeto que, carente de cualquier control social y familiar, puede devenir en criminal y cometer actos delictivos. El niño de la calle que se encuentra en el espacio liminar entre la ingenuidad y la malicia aparece en películas como Ciudad de Dios o Pixote.

¿Qué encuadre ideológico adopta el autor implícito en los cuentos de Julieta Pinto? El segundo, que podemos identificar en la literatura del siglo XIX en novelas como Oliver Twist y en cuentos como "La cerillera", de Hans Christian Andersen. Es un sujeto desvalido que debe ser objeto de las instituciones dedicadas al bienestar social de la niñez. No es el niño de la calle que reta a la autoridad, o que gasta gamberradas a los transeúntes, acciones típicas de este paradigma de representación. En todo caso, este paradigma, de amplia tradición, también evoluciona en el marco de la historia literaria y, en el plano temático, aparecen nuevos centros de interés, como la explotación sexual o el comercio ilegal de órganos. Si pensamos en la innovación o la tradición en la representación del chico de la calle, concluiremos que Julieta Pinto apuesta por la tradición. Reproduce situaciones típicas en la literatura de esta figura social.

\section{Notas}

1. Véase, como ejemplo de análisis de esta temática, el artículo de Pozo (2003) y Cuvardic García (2016, en prensa).

2. Véase un análisis del chico de la calle en el Capítulo XX de esta novela en Cuvardic García (2016, en prensa).
3. A partir de este momento, toda referencia y cita procedente de esta colección de cuentos pertenece a la siguiente edición: Julieta Pinto, Abrir los ojos, Heredia, EUNA, 2004.

4. Véase una evolución de los imaginarios de la ciudad de San José en el siglo XX en Araya (2010).

5. A partir de este momento, toda referencia y cita procedente de esta colección de cuentos pertenece a la siguiente edición: Julieta Pinto, A la vuelta de la esquina (2da edición). Heredia: EUNA, 1998.

6. En Cuvardic (2014) se puede leer un análisis del tópico del robo de la billetera del transeúnte que observa un escaparate. Es una acción protagonizada por el ratero, presente tanto en la escritura costumbrista como en la novela costarricense Candelaria del azar (2008), de Tatiana Lobo.

\section{Bibliografía}

Araya, María del Carmen 2010. De 'París en miniatura' al malestar en la ciudad. Medios de Comunicación e imaginarios urbanos. San José: EUNED.

Clarín (Leopoldo Alas). 2002. Dos solos de 'Clarín': Pipá y Doña Berta. Madrid: Anaya.

Congrains Martín, Enrique. 1986. "El niño de Junto al cielo". En: Seymour Menton (Ant.). El cuento hispanoamericano. México: Fondo de Cultura Económica, 531-546.

Cuvardic García, Dorde. 2014. "Relecturas del golfo de la calle decimonónico en la novela contemporánea costarricense: el 'pinta' en Candelaria del Azar, de Tatiana Lobo". En: Cécile Berti-Elisabeth (Dir.). Les récits de la marginalité en Amérique. Martinique: CaraïbéditionsUniversité, 143-171. 
Cuvardic García, Dorde. 2016 (en prensa). "El 'chico de la calle' en la historia de la literatura y la cultura visual latinoamericana: Los dorados, de Sergio Muñoz, Los olvidados, de Luis Buñuel, y Pixote, de Héctor Babenco". Actas del I Congreso de Literatura Comparada. San José: Universidad de Costa Rica.

Dufais, Sophie. 2011. "El niño de la calle y la ciudad fragmentada en la película Buenos Aires viceversa, de Alejandro Agresti”. En Hispanic Review 79(4): 615-637.

Fallas, Carlos Luis. 2008. Marcos Ramírez. San José: Editorial Costa Rica.

Fallas, Carlos Luis. 1995. Mi madrina. San José: Editorial Costa Rica.

Muñoz, Sergio. 1999. Los Dorados (Primera edición). San José, Costa Rica: Editores Alambique.

Muñoz, Sergio. 2009. Los Dorados (Segunda edición). San José, Costa Rica.

Pinto, Julieta. 1998. A la vuelta de la esquina (2da edición). Heredia: EUNA.
Pinto, Julieta. 2004. Abrir los ojos. Heredia: EUNA.

Pozo, Diego del 2003. “Olvidados y re-creados: la invariable y paradójica presencia del niño de la calle en el cine latinoamericano". En Chasqui 32(1): 85-97.

\section{Filmografía}

The Kid (1921). Director: Charles Chaplin. Producción: Charles Chaplin. Estados Unidos, 65 minutos.

Estación central de Brasil (Central do Brasil) (1998). Director: Walter Salles. Producción: Videofilmes-MACT Productions. Brasil, 115 minutos.

Los olvidados (1950). Director: Luis Buñuel. Producción: Ultramar Films. México, 88 minutos.

Pixote (1980). Director: Héctor Babenco. Producción: H.B. Filmes Unifilm. Brasil, 128 minutos.

Ciudad de Dios (2002). Director: Fernando Meirelles. Producción: Tulé Peak. Brasil, 130 minutos.

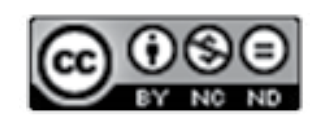

Este obra está bajo una licencia de Creative Commons Reconocimiento-NoComercial-SinObraDerivada 4.0 Internacional. 